\title{
Bicuculline-Sensitive Primary Afferent Depolarization Remains after Greatly Restricting Synaptic Transmission in the Mammalian Spinal Cord
}

\author{
Jacob Shreckengost, ${ }^{1}$ Jorge Calvo, ${ }^{2}$ Jorge Quevedo, ${ }^{2}$ and Shawn Hochman ${ }^{1}$ \\ ${ }^{1}$ Department of Physiology, Emory University School of Medicine, Atlanta Georgia 30322, and 2Departamento de Fisiología, Biofísica y Neurociencias, \\ Centro de Investigación y de Estudios Avanzados del Instituto Politécnico Nacional, C.P. 07300, México City, México
}

\begin{abstract}
Primary afferent neurotransmission is the fundamental first step in the central processing of sensory stimuli. A major mechanism producing afferent presynaptic inhibition is via a channel-mediated depolarization of their intraspinal terminals which can be recorded extracellularly as a dorsal root potential (DRP). Based on measures of DRP latency it has been inferred that this primary afferent depolarization (PAD) of low-threshold afferents is mediated by minimally trisynaptic pathways with GABAergic interneurons forming last-order axoaxonic synapses onto afferent terminals. We used an in vitro rat spinal cord preparation under conditions that restrict synaptic transmission to test whether more direct low-threshold pathways can produce PAD. Mephenesin or high divalent cation solutions were used to limit oligosynaptic transmission. Recordings of synaptic currents in dorsal horn neurons and population synaptic potentials in ventral roots provided evidence that conventional transmission was chiefly restricted to monosynaptic actions. Under these conditions, DRP amplitude was largely unchanged but with faster time to peak and reduced duration. Similar results were obtained following stimulation of peripheral nerves. Even following near complete block of transmission with high $\mathrm{Mg}^{2+} / \mathrm{low} \mathrm{Ca}^{2+}$-containing solution, the evoked DRP was reduced but not blocked. In comparison, in nominally $\mathrm{Ca}^{2+}$-free or EGTA-containing solution, the DRP was completely blocked confirming that $\mathrm{Ca}^{2+}$ entry mediated synaptic transmission is required for DRP genesis. Overall these results demonstrate that PAD of low-threshold primary afferents can occur by more direct synaptic mechanisms, including the possibility of direct negative-feedback or nonspiking dendroaxonic pathways.
\end{abstract}

\section{Introduction}

The spinal cord receives a continuous barrage of sensory information that requires central mechanisms to limit and channel their signaling. A principal cellular mechanism for control of primary sensory afferents is via a depolarization of their terminals, termed primary afferent depolarization (PAD) which leads to a reduction in transmitter release. PAD can be measured experimentally following its antidromic electrotonic spread to dorsal roots as a dorsal root potential (DRP).

To date, electrophysiological experiments in the adult cat relying on measures of central latency have suggested that PAD of low-threshold cutaneous and muscle afferents is produced via a minimally trisynaptic pathway involving last order GABAergic inhibitory interneurons (Rudomin and Schmidt, 1999). In contrast, recent anatomical evidence demonstrated that only a single interneuron is interposed in some disynaptic circuits that could

\footnotetext{
Received Aug. 7, 2009; revised Jan. 15, 2010; accepted March 2, 2010.

S.H. was supported by the Christopher and Dana Reeve Foundation and the Craig Neilsen Foundation. J.Q. was supported by Consejo Nacional de Ciencia y Tecnología 59873, Mexico.

Correspondence should be addressed to either of the following: Dr. Shawn Hochman, Whitehead Biomedica Research Building, Room 644, Emory University School of Medicine, 615 Michael St., Atlanta GA 30322, E-mail: shawn.hochman@emory.edu; or Jorge Quevedo, Departamento de Fisiología, Biofísica y Neurociencias, IINVESTAV del IPN, Av. IPN, 2508, Col. San Pedro Zacatenco, C.P. 07300, México City, México, E-mail: jquevedo@fisio. cinvestav.mx.

D0I:10.1523/JNEUROSCI.3873-09.2010

Copyright $\odot 2010$ the authors $\quad 0270-6474 / 10 / 305283-06 \$ 15.00 / 0$
}

produce PAD of lower threshold afferents (Olave et al., 2002; Bannatyne et al., 2009). In addition, nonspiking spinal microcircuits in turtle have been shown to be sufficient to generate afferent-evoked PAD in TTX-insensitive high-threshold afferents, further implicating more direct negative feedback mechanisms controlling afferent activity (Russo et al., 2000).

We designed experiments to provide the first electrophysiological evidence that lower-threshold afferents also evoke PAD by more direct synaptic pathways. We used the isolated hemisected juvenile rat spinal cord maintained in vitro and examined the effects of chemically induced reductions in synaptic transmission on the DRP and on the excitability of spinal neurons. Our rationale was that if synaptic transmission could be limited principally to monosynaptic actions and the earliest DRP component is largely unaffected, then PAD evoked by stimulation of low-threshold afferents can be produced by more direct mechanisms. Indeed, the results presented suggest that more direct mechanisms, not mediated by trisynaptic or polysynaptic pathways, represent the predominant form of primary afferent stimulation-evoked PAD.

\section{Materials and Methods}

All procedures were approved by the Emory University Institutional Animal Care and Use Committee. Midsagittally hemisected spinal cords were isolated from Sprague Dawley rats aged from postnatal days 7-14 and were prepared for in vitro experiments as described previously (Shay et al., 2005; Machacek and Hochman, 2006). Recordings were made in 
A

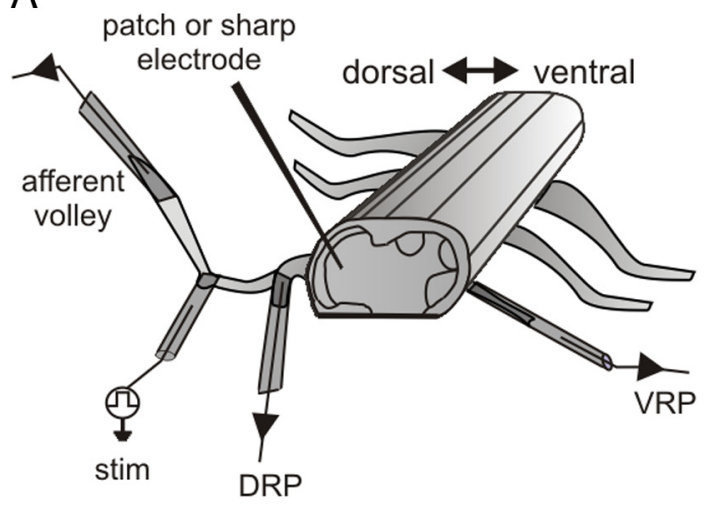

$\mathrm{Bi}$
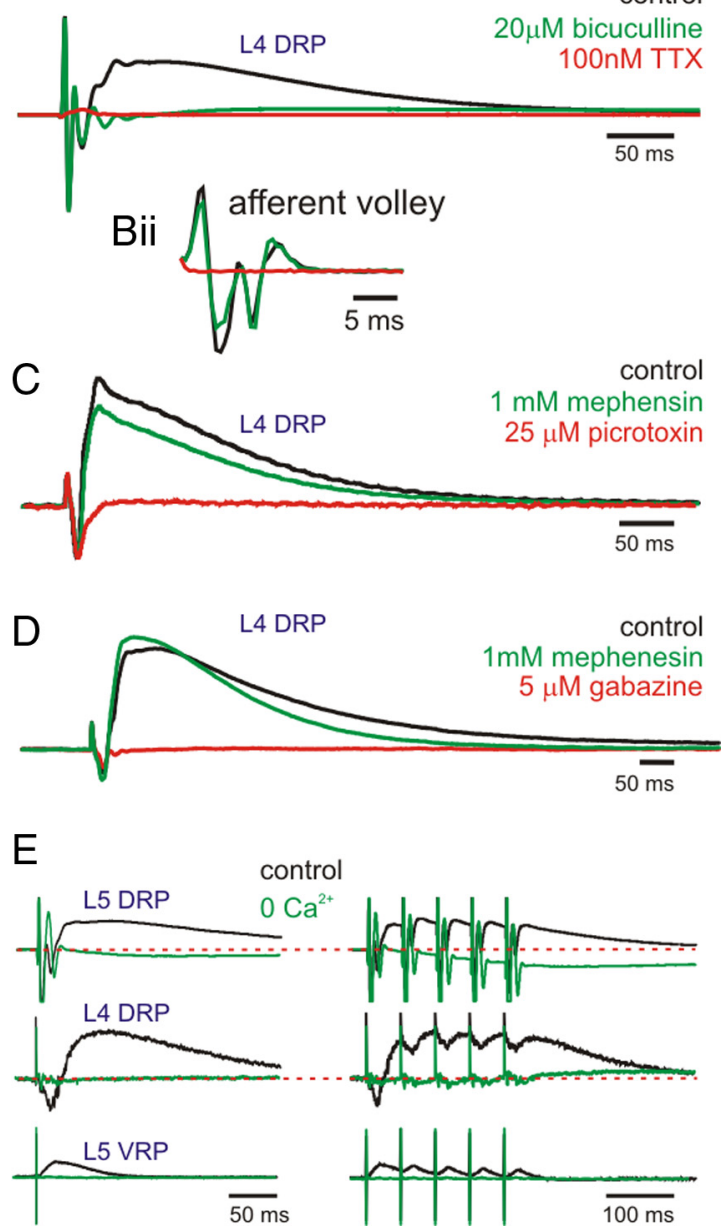

Figure 1. A, Experimental setup (see Materials and Methods for details). $\boldsymbol{B}-\boldsymbol{D}$, Stimulation is via the $L 5$ dorsal root at $100 \mu \mathrm{A}, 100 \mu \mathrm{s}$. Bi, A single stimulus produces a DRP that is almost entirely blocked by bicuculline. The remaining potential is TTX-sensitive. Bii, Low-threshold activation is confirmed by measuring the afferent volley produced by this stimulation and its TTX sensitivity. C, Picrotoxin completely blocks DRP after synaptic isolation with mephenesin. $\boldsymbol{D}$, Similarly, gabazine blocks the DRP after preincubation in mephenesin. $\boldsymbol{E}$, The DRP requires chemical synaptic transmission. Evoked responses are shown before and after bath exchange to a nominally $\mathrm{OCa}^{2+}$-containing saline. Identical results were seen in another animal after application of the $\mathrm{Ca}^{2+}$ chelator EGTA $(100 \mu \mathrm{M})$. Left column is a single shock and right column is five pulses at $20 \mathrm{~Hz}$. Traces were low-pass filtered at $300 \mathrm{~Hz}$.

oxygenated aCSF containing the following (in $\mathrm{mm}$ ): $\mathrm{NaCl} 128 ; \mathrm{KCl} 1.9$; D-glucose 10; $\mathrm{MgSO}_{4}$ 1.3; $\mathrm{CaCl}_{2} 2.4 ; \mathrm{KH}_{2} \mathrm{PO}_{4} 1.2$; and $\mathrm{NaHCO}_{3} 26$.

The general experimental setup is shown in Figure 1. Dorsal lumbar roots (L3, L4 and/or L5) were left intact for stimulation of afferent fibers broadly separated by electrical stimulus intensity with bipolar glass suction electrodes. For some experiments, the tibial and deep peroneal hindlimb peripheral nerves were left intact for stimulation. DRPs were recorded from cut dorsal root filaments or intact via en passant nerve suction. Ventral root potentials (VRPs) and accompanying reflexes were recorded from the ventral motor roots. Unless otherwise stated, recordings were made with differential amplifiers at DC with a gain of 1000 (AM Systems Model 3000) or near DC (high-pass at $0.1 \mathrm{~Hz}$; custom built) with a gain of 10,000. Unless otherwise stated, constant current stimulators delivered single-shock stimuli every $30 \mathrm{~s}$ of defined stimulation intensity to the dorsal roots (usually L5) or peripheral nerves. Occasionally, a train of 5 pulses at $20 \mathrm{~Hz}$ was delivered $15 \mathrm{~s}$ after the single-shock stimulus. All actions are studied from large diameter/fast conducting myelinated lowthreshold afferents (cutaneous $\mathrm{A} \beta$ and muscle group I and II), typically at constant current stimulation values of $100 \mu \mathrm{A}, 100 \mu \mathrm{s}$ (Shay et al., 2005) which equated to simulation at $\sim 10$ times the threshold (T) for afferent fiber recruitment. In most experiments, the afferent volley was recorded antidromically distal to the site of stimulation to confirm selective recruitment of low-threshold afferents (Shay et al., 2005) and to monitor volley amplitudes during drug applications to ensure observed actions are independent of changes in afferent fiber recruitment. This is critical in the current work as the solutions used to minimize synaptic transmission presumably do so by raising action potential threshold (Frankenhaeuser and Meves, 1958; Ono et al., 1979). A suprathreshold stimulation intensity of 100 $\mu \mathrm{A}, 100 \mu$ s prevented such actions on afferent fiber recruitment. Whenever tested, the afferent volley and central actions were completely eliminated at low TTX dose (100-200 nM) supporting an absence of contribution from high-threshold afferents (Fig. 1B).

To minimize di- and trisynaptic transmission, mephenesin (Sigma) at $1 \mathrm{~mm}$ or a high divalent cation aCSF containing $8 \mathrm{~mm} \mathrm{Mg}^{2+} / 4 \mathrm{~mm} \mathrm{Ca}^{2+}$ was used (Jahr and Yoshioka, 1986). To greatly diminish synaptic transmission a $6.5 \mathrm{~mm} \mathrm{Mg}^{2+} / 0.85 \mathrm{~mm} \mathrm{Ca}^{2+}$ aCSF solution (Vyklický et al., $1976)$ or 100-500 $\mu \mathrm{M}$ EGTA were used. Bicuculline (10-20 $\mu \mathrm{M})$, picrotoxin $(25 \mu \mathrm{M})$ and gabazine $(5 \mu \mathrm{M})$ (Sigma) were used to block transmission through $\mathrm{GABA}_{\mathrm{A}}$-like receptors. In all cases, control DRP responses were recorded for $1 \mathrm{~h}$, and the effects of drugs or solute exchange were recorded for a minimum of $30 \mathrm{~min}$ before washout and return to control aCSF.

Whole-cell patch-clamp recordings. Whole-cell patch-clamp recordings were made as detailed previously (Machacek and Hochman, 2006) to record evoked postsynaptic events after stimulation of attached roots. Patch electrodes contained (in mM); $140 \mathrm{~K}$-gluconate, 11 EGTA, 10 HEPES, $1 \mathrm{CaCl}_{2}$, and $35 \mathrm{KOH}$ or $120 \mathrm{CsF}, 10 \mathrm{EGTA}, 10 \mathrm{HEPES}, 10 \mathrm{CsCl} 2$, $35 \mathrm{CsOH}$, and $5 \mathrm{QX} 314$ (to block spiking) at $\mathrm{pH}$ 7.3. Electrode resistances ranged from 2 to $6 \mathrm{M} \Omega$. Recordings were obtained in conjunction with an Axopatch 1D amplifier filtered at $2 \mathrm{kHz}$ (Molecular Devices). Synaptic events were recorded at the same membrane potential before, during, and after drug application. Recordings targeted the deep dorsal horn, the predominant termination site of low-threshold primary afferents(Willis and Coggeshall, 1991) and approximate location of putative interneurons interposed in PAD pathways (Jankowska et al., 1981). Primary afferent stimulation-evoked EPSCs were selected for and confirmed by the persistence of monosynaptic inward currents when the holding potential was raised to $-40 \mathrm{mV}$. Monosynaptic currents were confirmed by latency to onset and onset consistency during $1 \mathrm{~Hz}$ stimulation (Bardoni et al., 2004). Only neurons with clear monosynaptic EPSCs were included in the analysis.

Data analysis. Data were acquired and analyzed on a personal computer using either pClamp software (version 10.0; Molecular Devices) or files were imported into MATLAB for analysis with a custom program. The last 5 sweeps of each recording were averaged $30 \mathrm{~min}$ after drug application or washout. Each sweep was $30 \mathrm{~s}$ in duration with a single stimulus pulse delivered at sweep onset. The resulting traces were then used to determine peak amplitudes, time to peak, duration, and area of DRPs and EPSCs. Values are reported as mean \pm SE. Student's $t$ test was used to determine statistical significance. Unless otherwise stated, $p<0.05$ was considered as significant. 


\section{Results}

PAD requires synaptic transmission, TTX-sensitive afferents, and is blocked by $\mathrm{GABA}_{\mathrm{A}}$ receptor antagonists

At the stimulus intensity chosen we first demonstrated that the PAD measured with DRP recordings is generated by lowthreshold afferents. Low-threshold afferent-evoked DRPs are sensitive to $\mathrm{GABA}_{\mathrm{A}}$ receptor antagonists, as shown previously (Rudomin and Schmidt, 1999). Here, we demonstrate that the DRP is abolished by the GABA receptor antagonists bicuculline $(n=13 / 13)$, picrotoxin $(n=2 / 2)$, and gabazine $(n=2 / 2$; Fig. $1 B-D)$. To further confirm that we are looking at a low-threshold afferent fiber population, we applied low-dose TTX (100-200 $\mathrm{nM}$ ) on several occasions and always blocked the DRP and afferent volley $(n=8 / 8)$ (Fig. $1 B)$.

While it is assumed that PAD is mediated by chemical synaptic transmission, this has not been tested in the mammal and may not apply to all afferent-evoked responses (Vyklický et al., 1976). To demonstrate that chemical synaptic transmission is essential to the DRP generated following stimulation of low-threshold afferents we perfused the cord in a nominally $\mathrm{Ca}^{2+}$-free $\operatorname{aCSF}(n=$ 4/4) (Fig. $1 E)$ or by applying the $\mathrm{Ca}^{2+}$ chelator EGTA $(n=2 / 2)$. In both the heteronymous L4 dorsal root and the L5 ventral root the depolarizing potentials were completely abolished.

\section{Mephenesin or high divalent cation solution largely restricts transmission to monosynaptic actions}

We explored whether PAD can be generated via more direct synaptic actions previously estimated to be minimally trisynaptic. To achieve this, we minimized synaptic transmission with bath applied mephenesin or exchanged the bath to a high divalent cation aCSF. At $10 \mathrm{~T}$ or $100 \mu \mathrm{A}, 100 \mu \mathrm{s}$, neither mephenesin nor high divalent cation solution had a significant depressant effect on the peak amplitude of the DRP produced by fast conducting afferent fibers $(95 \pm 12 \% n=14$ and $74.0 \pm 14 \% n=11$, respectively). After restriction of synaptic actions by mephenesin or high divalent cation solution, the remaining DRP was still completely blocked by all $\mathrm{GABA}_{\mathrm{A}}$ receptor antagonists tested $(n=$ 12) with examples for picrotoxin and gabazine illustrated in Figure $1, C$ and $D$.

Extracellular field potentials (EFPs) evoked by afferent nerve stimulation predominantly reflect the population monosynaptic EPSPs of nearby neurons (Baldissera et al., 1981). EFPs were recorded in the deep dorsal horn. As shown in Figure 2, Ai and Aii, stimuli delivered at $10 \mathrm{~T}$ produced two field potentials corresponding to the two fast conducting low-threshold afferent volleys activated at this stimulation intensity. The afferent volleys and evoked monosynaptic field potentials were unaltered by mephenesin (Fig. 2Ai) and slightly altered by the high divalent cation solution (Fig. 2Aii).

We next examined the effects of mephenesin and high divalent cation solution on longer latency synaptic actions. Concomitant recordings of ventral root reflexes including DC-coupled VRPs were used to monitor population synaptic actions in motoneurons (Rudomin et al., 1987). Both mephenesin and the high divalent cation solutions isolated monosynaptic reflexes $(n=5 / 5$ and $3 / 3$, respectively) and shorter latency, presumably monosynaptic subthreshold population VRPs $(n=10 / 10$ and 6/6, respectively; Fig. 2 Aiii). Combined the DC-coupled VRP duration was reduced to $66 \pm 11 \%$ of control values $(n=9 ; p<0.05)$ due to a significantly reduced rise area $(59 \pm 7 \%$ of control value; $p<$ $0.01)$ and decay area $(60 \pm 11 \%$ of control; $p<0.01)$, while the monosynaptic reflex amplitude was not significantly reduced $(79.8 \pm 11.4 \%$ of control).
Voltage-clamp recordings from spinal neurons of afferentevoked postsynaptic currents were used to provide further evidence of pharmacological block of polysynaptic actions. The deep dorsal horn was targeted as this is the site where PAD interneurons have been identified (Jankowska et al., 1981) and where a large fraction of low-threshold primary afferents terminate (Willis and Coggeshall, 1991). Intracellular recordings demonstrated a near-complete block of longer latency synaptic currents in the presence of mephenesin $(n=5 / 5)$ and a high divalent cation solution $(n=7 / 7$; Fig. $2 B)$. Monosynaptic actions remained and, where measurable, remained unchanged in peak amplitude. Note that the blocked longer-latency synaptic currents may appear to have latencies too long to be generated disynaptically. However, this is hard to ascertain since synaptic current onset cannot be measured due to the presence of an overlapping monosynaptic effect and conduction times of lowthreshold afferents at this age may lead to large latency delays (Shay et al., 2005). Table 1, EPSCs, shows that for both mephenesin and high divalent cation-containing solution, the overall area of decay was significantly reduced. In addition EPSC duration was significantly reduced overall to $48 \pm 15 \%$ for mephenesin and to $74 \pm 27 \%$ for a high divalent cation solution.

\section{Bicuculline-sensitive DRPs remain after restricting synaptic transmission}

Overall, the above results support the use of mephenesin and high divalent cation solution to largely restrict transmission to monosynaptic actions. Critically, under these conditions, lowthreshold DRPs remained with $1 \mathrm{~mm}$ mephenesin $(n=14 / 14$; Figs. $1 C, D, 2$ Bii, Cii, $D$ ) or after replacement with a high divalent cation solution ( $8 \mathrm{mM} \mathrm{Mg}^{2+} / 4 \mathrm{mM} \mathrm{Ca}^{2+} ; n=11 / 11$; Fig. $2 \mathrm{Aiii}, \mathrm{Bi}, \mathrm{Ci}$ ). DRP peak amplitude was not statistically different after application of these agents whereas average DRP duration was significantly reduced (from $471 \pm 34 \mathrm{~ms}$ to $312 \pm 71 \mathrm{~ms}$; see also Table 1, Dorsal root potentials). In addition, time to DRP peak was significantly reduced by mephenesin and the areas of DRP rise and decay were reduced for both agents (Table 1, Dorsal root potentials).

Further comparison of mephenesin to the high divalent cation solution shows that both block later components of the DRP (Fig. $2 C)$. In this example the high divalent cation solution also reduces the early component of the DRP.

In some experiments, peripheral nerves were left in continuity. The tibial and deep peroneal nerve were stimulated at $4 \mathrm{~T}$ and $10 \mathrm{~T}$ and at both stimulation intensities, mephenesin at $1 \mathrm{~mm}$ blocked only a small portion of the DRP (Fig. 2 Di,Dii). For tibial, DRP amplitude was reduced to $81 \%$ at $4 \mathrm{~T}(n=4)$ and $69 \%$ of the original values at $10 \mathrm{~T}(n=3)$. For deep peroneal these values are 76 and $81 \%$, respectively $(n=3)$. In all instances short-latency EFP amplitudes were unchanged (data not shown).

\section{Further evidence of minimal synaptic transmission requirements in afferent-evoked $\mathrm{PAD}$}

We used a $6.5 \mathrm{mM} \mathrm{Mg}^{2+} / 0.85 \mathrm{mM} \mathrm{Ca}^{2+}$ solution to severely minimize synaptic transmission (Vyklický et al., 1976). Under these conditions the DRP is either almost completely blocked (heteronymous root; data not shown) or a small component remains (homonymous root) $(n=4 / 4 ; 10 \pm 4 \%$ of control; Fig. $3 A i)$. However, following repetitive stimulation with 5 pulses at $20 \mathrm{~Hz}$, the heteronymous DRP reemerges (data not shown) and the homonymous DRP facilitates. This demonstrates that even with only minimal chemical synaptic transmission, a lowthreshold DRP is evoked via more direct actions of afferents on 
their terminals. Recordings from monosynaptically connected interneurons show a nearly identical phenomenon where repetitive stimulation is required to observe postsynaptic currents in these interneurons $(n=4 / 4$; Fig. 3 Aii $)$.

\section{Discussion}

The present study challenged the assumption based exclusively on latency measures that PAD predominantly involves a minimally trisynaptic pathway involving excitatory and GABAergic interneurons (Eccles et al., 1962; Jankowska et al., 1981; Rudomin and Schmidt, 1999). After applying solutions thought to block all but monosynaptic transmission, the evoked DRP was not significantly diminished in amplitude (Table 1, Dorsal root potentials). This is consistent with an earlier in vivo report on the actions of mephenesin (Farkas et al., 1989). Evidence of synaptic isolation was corroborated with intracellular recordings in dorsal horn neurons showing block of longer latency excitatory currents and reduced duration of population synaptic actions in motoneurons by recording their electrotonic spread as a VRP. VRPs and EFPs monitor population responses confirming a decrease in polysynaptic actions after application of mephenesin or a high divalent cation solution. We verified that the afferent fiber population recruited was the fastest conducting TTX-sensitive fibers. The evoked DRP was blocked using $\mathrm{GABA}_{\mathrm{A}}$ receptor antagonists, demonstrating that the DRP involves activation of $\mathrm{GABA}_{\mathrm{A}}$ or $\mathrm{GABA}_{\mathrm{A}}$ like receptors. Even stronger evidence for PAD being produced by more direct mechanisms was demonstrated by its expression even under conditions of nearcomplete block of synaptic transmission with a high $\mathrm{Mg}^{2+} /$ low $\mathrm{Ca}^{2+}$ aCSF.

The most conservative interpretation of our findings is that PAD of many lowthreshold afferents does not require trisynaptic pathways but does use disynaptic axoaxonic pathways. Under such conditions PAD-producing interneurons are still recruited during mephenesin or highdivalent cation solution-induced reductions in transmission. While probably a component, di- and polysynaptic pathways are unlikely the dominant mechanism for the early DRP as its amplitude was only slightly depressed when longer latency synaptic actions (EPSCs and VRPs) were largely abolished.

The identity of the low-threshold afferents by which more direct pathways produce $\mathrm{PAD}$ requires future investigation. For example, PAD generated by
DR L5 10T
$\mathrm{Ai}$

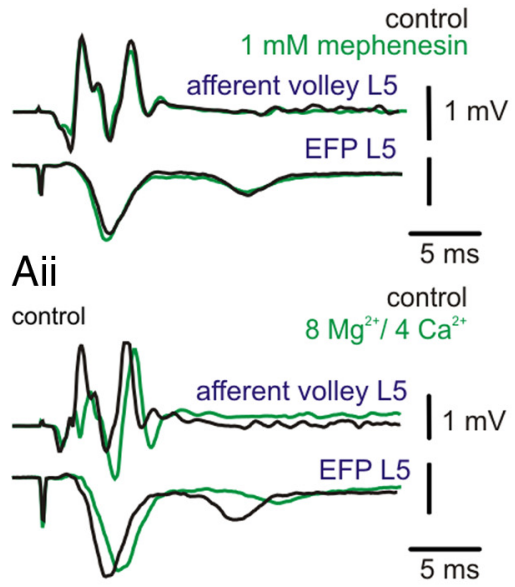

Bi interneuron

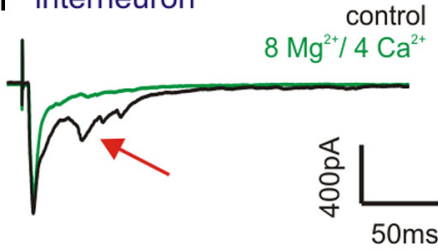

Ci DRP L4

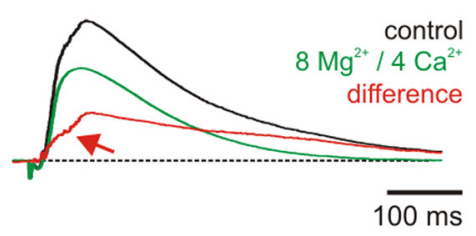

Di DRP L4
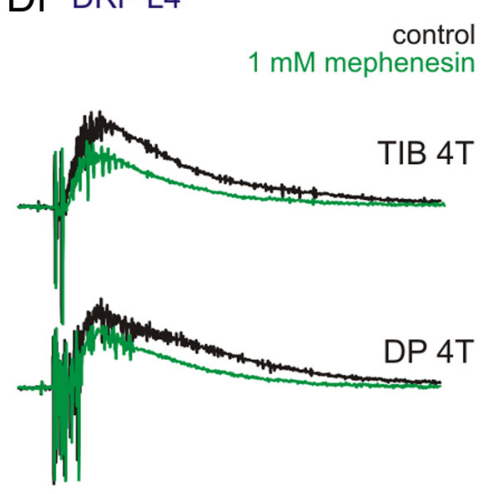

Aiii

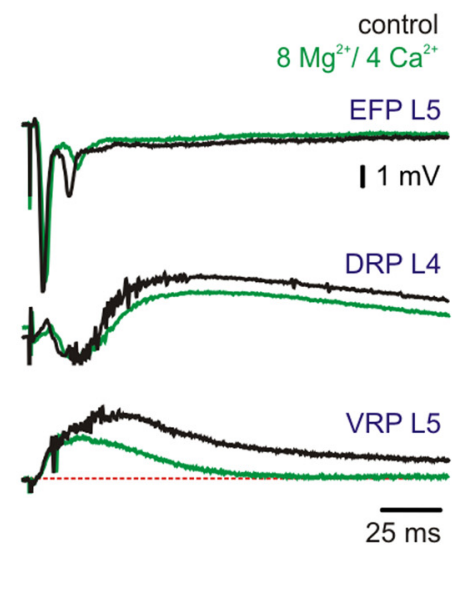

Bii interneuron

control

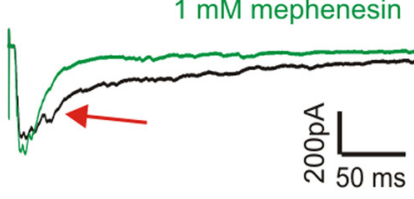

Cii DRP L4

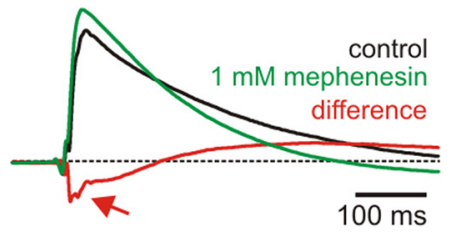

Dii DRP L4

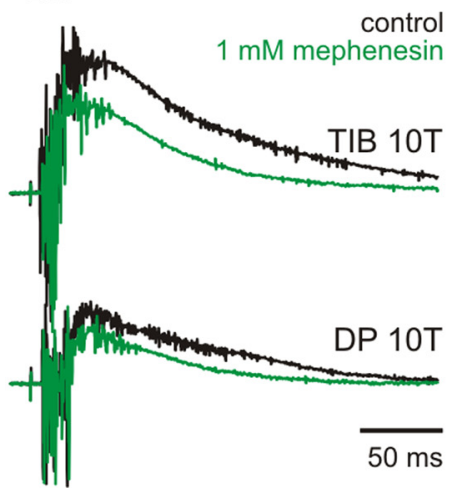

Figure 2. A, Relation between afferent volleys and evoked field potentials. Stimuli were delivered at $10 T$ to the L5 dorsal root. Afferent volleys were recorded from the same dorsal root. Extracellular field potentials (EFPs) were recorded in the $L 5$ deep dorsal horn. $\boldsymbol{A}$, Stimulation recruits 2 separable afferent volleys, each leading to a monosynaptic field potential. These responses are unaffected by the presence of mephenesin. Aii, In the presence of a high divalent cation solution, the low-threshold afferent volley waveforms and corresponding evoked field potentials are slowed. Aiii, Relation of monosynaptic EFPs to the evoked DRP and VRPs. The evoked DRP waveform shape is largely unchanged in the presence of the high divalent cation solution whereas VRP duration is greatly shortened. Bi, Bii, EPSCs in 2 neurons measured at a holding potential of $-80 \mathrm{mV}$. Identity of synaptic current was verified as excitatory at a holding potential of $-40 \mathrm{mV}$. Under both conditions (high $\mathrm{Mg}^{2+} / \mathrm{high} \mathrm{Ca}^{2+}$ and mephenesin) the longer-latency synaptic response (at arrow) is blocked while the monosynaptic component is not significantly affected. Ci, Cii, High divalent cation solution and mephenesin both block longer latency DRPs in the same animal (arrows on difference trace identifying inflection of longer-latency component). $D$, Similarly, most of the DRP remains after treatment with mephenesin following stimulation of the tibial or deep peroneal nerve at 4T (Di) or 10T (Dii). Traces were low-pass filtered at $3 \mathrm{kHz}$ and at $300 \mathrm{~Hz}$ in $\boldsymbol{C}$. 
Table 1. Effects of $1 \mathrm{~mm}$ mephenesin- and high divalent cation-containing solutions on dorsal root potential and EPSCs

\begin{tabular}{|c|c|c|c|c|c|c|}
\hline & & Peak amplitude (\% control) & Time to peak (\% control) & Duration (\% control) & Area of rise (\% control) & Area of decay (\% control) \\
\hline \multicolumn{7}{|l|}{ Dorsal root potentials } \\
\hline Mephenesin (1 mм) & $n=14$ & $94.7 \pm 11.7$ & $81.7 \pm 5.2^{* *}$ & $66.6 \pm 3.8^{* *}$ & $77.35 \pm 8.7^{*}$ & $69.0 \pm 8.2^{* *}$ \\
\hline Wash & $n=8$ & $109.7 \pm 30.0$ & $102.1 \pm 9.2$ & $75.0 \pm 8.4^{*}$ & $120.7 \pm 28.4$ & $90.8 \pm 24.9$ \\
\hline High $\mathrm{Mg}^{2+} /$ high $\mathrm{Ca}^{2+}$ & $n=11$ & $74.0 \pm 14.4$ & $109.7 \pm 14.5$ & $74.6 \pm 4.0^{* *}$ & $61.3 \pm 10.5^{* *}$ & $54.1 \pm 10.1^{* *}$ \\
\hline Wash & $n=8$ & $76.0 \pm 15.6$ & $113.6 \pm 9.3$ & $90.8 \pm 4.2$ & $96.8 \pm 17.5$ & $71.4 \pm 15.5$ \\
\hline \multicolumn{7}{|l|}{ EPSCS } \\
\hline Mephenesin (1 mм) & $n=4$ & $114.1 \pm 37.7$ & $114.8 \pm 13.7$ & $48.3 \pm 14.9^{*}$ & $94.9 \pm 18.6$ & $21.1 \pm 4.6^{* *}$ \\
\hline Wash & $n=4$ & $110.6 \pm 32.8$ & $129.4 \pm 33.7$ & $71.0 \pm 23.0$ & $94.5 \pm 16.1$ & $36.7 \pm 14.7^{*}$ \\
\hline High $\mathrm{Mg}^{2+} /$ high Ca $^{2+}$ & $n=7$ & $66.2 \pm 20.4$ & $81.6 \pm 12.5$ & $73.8 \pm 27.7^{*}$ & $60.5 \pm 18.4$ & $23.8 \pm 3.6^{* *}$ \\
\hline Wash & $n=6$ & $98.9 \pm 25.0$ & $104.9 \pm 9.9$ & $97.6 \pm 50.2$ & $86.1 \pm 17.9$ & $52.1 \pm 14.5^{*}$ \\
\hline
\end{tabular}

Values represent percentage of control reported as mean \pm SE. Time to peak was measured from where the signal crosses baseline to the peak of the DRP. DRP or EPSC duration is the measure of the signal crossing baseline to the point at which the DRP decayed to $10 \%$ of the peak value. Area of rise represents the area under the curve from where the signal crosses baseline to the time of peak amplitude. Area of decay represents the area under the curve from the time of peak amplitude to the time point where the signal decays to $10 \%$ of the peak value. ${ }^{*} p<0.05 ;{ }^{* *} p<0.01$.
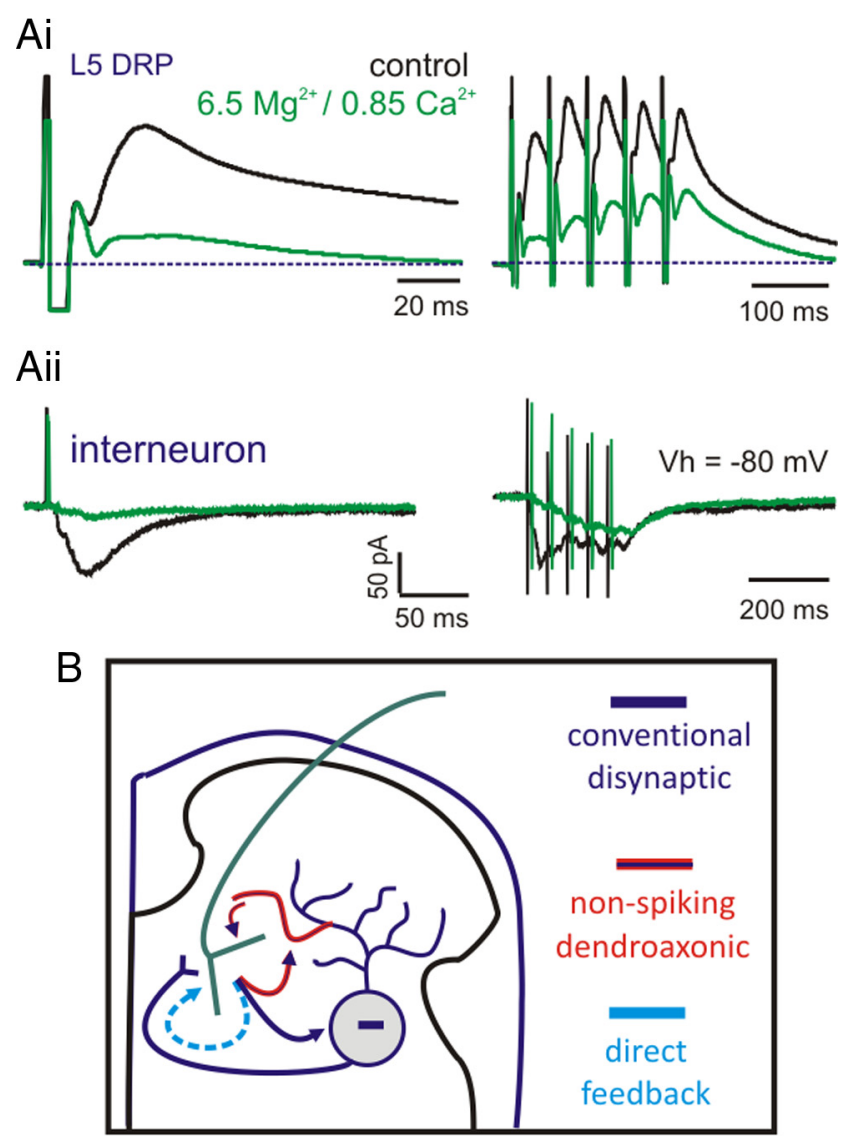

Figure 3. A, Greatly reducing synaptic transmission does not completely block the DRP. Evoked responses are shown before and after bath exchange to a high $\mathrm{Mg}^{2+} / \mathrm{low} \mathrm{Ca}^{2+}$ saline $\left(6.5 \mathrm{~mm} \mathrm{Mg}^{2+} / 0.85 \mathrm{mmCa}^{2+}\right)$.Stimulation is via the L5 dorsal root at $100 \mu \mathrm{A}, 100 \mu \mathrm{s}$. Ai, Left, Single shock; right, five pulses at $20 \mathrm{~Hz}$. In high $\mathrm{Mg}^{2+} / \mathrm{low} \mathrm{Ca}^{2+}$ saline, the DRP is facilitated following repetitive stimulation. Aii, Under the same conditions in another animal, the high $\mathrm{Mg}^{2+} /$ low $\mathrm{Ca}^{2+}$ saline virtually abolished monosynaptic EPSCs, but transmission is increased by repetitive stimulation (upper row). Traces were low-pass filtered at $300 \mathrm{~Hz}$. B, Putative circuits for low-threshold afferent-evoked PAD not requiring trisynaptic pathways. As mephenesin and high divalent cation solutions block part of the DRP, a conventional disynaptic pathway may serve PAD of some primary afferents. The remaining DRP may arise from direct monosynaptic actions of transmitter onto afferent terminals or via a disynaptic nonspiking dendroaxonic microcircuit. For details see Discussion.

some afferents may require minimally trisynaptic pathways on some afferents but may generate more direct negative feedback onto homonymous terminals (Wall, 1958; Olave et al., 2002; Bannatyne et al., 2009). Regardless, given that most of the DRP remains after synaptic transmission reduction, it seems likely that many low-threshold afferents produce PAD by more direct circuits.

\section{Is PAD generated monosynaptically or via unconventional nonspiking microcircuits?}

The most straightforward interpretation of the data is that a major component of the DRP is generated by direct monosynaptic or extrasynaptic negative feedback mechanisms. Direct feedback would require that primary afferents release transmitter(s) acting on $\mathrm{GABA}_{\mathrm{A}}$ or $\mathrm{GABA}_{\mathrm{A}}$-like receptors, but numerous labeling studies have failed to support GABA as a transmitter localized in primary afferents (Todd, 1996). Alternate candidate amino acids are taurine and $\beta$-alanine, as both activate $\mathrm{GABA}_{\mathrm{A}}$ receptors to produce PAD (Nicoll and Alger, 1979). Microdialysis experiments demonstrate taurine and $\beta$-alanine release following activation of primary afferents by as much as glutamate (Paleckova et al., 1992). There is also evidence of taurine-immunoreactive primary afferents (Lee et al., 1992).

Another possibility is that acetylcholine (ACh) is coreleased from primary afferents to act on bicuculline-sensitive nicotinic receptors. Peripheral choline acetyltransferase (pChAT) is found in both small and large diameter primary afferents (Bellier and Kimura, 2007) and immunolabeling studies identify pChAT in myelinated dorsal column primary afferents (Yasuhara et al., 2008). Large-diameter afferents preferentially express the vesicular ACh transporter as well as acetylcholinesterase (Willis and Coggeshall, 1991; Tata et al., 2004; Bellier and Kimura, 2007). Primary afferents also contain bicuculline-sensitive $\alpha 9$ and $\alpha 10$ nicotinic ACh receptor subunits (Rothlin et al., 1999; Lips et al., 2002; Alexander et al., 2007) and preliminary results demonstrate reduction in DRP amplitude by nicotinic receptor antagonists with reported actions on $\alpha 9$ receptors (Hochman et al., 2010).

It is also possible that PAD is produced by disynaptic dendroaxonic pathways. In turtle, a nonspiking microcircuit generates a DRP evoked following stimulation of high-threshold TTXinsensitive fibers (Russo et al., 2000). Primary afferents contain numerous dendroaxonic synapses (Alvarez, 1998) so it is conceivable that microcircuits based on these synapses produce $\mathrm{PAD}$ at various low-threshold afferents and these actions would be resistant to mephenesin and high divalent cation solutions. This would also be consistent with DRPs seen under conditions of minimal transmission where postsynaptic spiking would not be required.

Figure $3 B$ summarizes these possibilities. 


\section{References}

Alexander SP, Mathie A, Peters JA (2007) Transmitter-gated channels. Br J Pharmacol 150 [Suppl 1]:S82-S95.

Alvarez FJ (1998) Anatomical basis for presynaptic inhibition of primary sensory fibers. In: Presynaptic inhibition and neural control (Rudomin P, Romo R, Mendell L, eds), pp 13-49. New York: Oxford UP.

Baldissera F, Hultborn H, Illert M (1981) Integration in spinal neuronal systems. In: Handbook of physiology, Section I: The nervous system, pp 509-595. Baltimore: Williams \& Wilkins.

Bannatyne BA, Liu TT, Hammar I, Stecina K, Jankowska E, Maxwell DJ (2009) Excitatory and inhibitory intermediate zone interneurons in pathways from feline group I and II afferents: differences in axonal projections and input. J Physiol 587:379-399.

Bardoni R, Torsney C, Tong CK, Prandini M, MacDermott AB (2004) Presynaptic NMDA receptors modulate glutamate release from primary sensory neurons in rat spinal cord dorsal horn. J Neurosci 24:2774-2781.

Bellier JP, Kimura H (2007) Acetylcholine synthesis by choline acetyltransferase of a peripheral type as demonstrated in adult rat dorsal root ganglion. J Neurochem 101:1607-1618.

Eccles JC, Magni F, Willis WD (1962) Depolarization of central terminals of Group I afferent fibres from muscle. J Physiol 160:62-93.

Farkas S, Tarnawa I, Berzsenyi P (1989) Effects of some centrally acting muscle relaxants on spinal root potentials: a comparative study. Neuropharmacology 28:161-173.

Frankenhaeuser B, Meves H (1958) The effect of magnesium and calcium on the frog myelinated nerve fibre. J Physiol 142:360-365.

Hochman S, Shreckengost J, Kimura H, Quevedo J (2010) Presynaptic inhibition of primary afferents by depolarization: observations supporting non-traditional mechanisms. In: Cellular and network functions in the spinal cord (Ziskind-Conhaim L, Fetcho JR, Hochman S, MacDermott $\mathrm{AB}$, Stein PSG, eds), in press. New York: Wiley.

Jahr CE, Yoshioka K (1986) Ia afferent excitation of motoneurones in the in vitro new-born rat spinal cord is selectively antagonized by kynurenate. J Physiol 370:515-530.

Jankowska E, McCrea D, Rudomín P, Sykova E (1981) Observations on neuronal pathways subserving primary afferent depolarization. J Neurophysiol 46:506-516.

Lee IS, Renno WM, Beitz AJ (1992) A quantitative light and electron microscopic analysis of taurine-like immunoreactivity in the dorsal horn of the rat spinal cord. J Comp Neurol 321:65-82.

Lips KS, Pfeil U, Kummer W (2002) Coexpression of alpha 9 and alpha 10 nicotinic acetylcholine receptors in rat dorsal root ganglion neurons. Neuroscience 115:1-5.

Machacek DW, Hochman S (2006) Noradrenaline unmasks novel self- reinforcing motor circuits within the mammalian spinal cord. J Neurosci 26:5920-5928

Nicoll RA, Alger BE (1979) Presynaptic inhibition: transmitter and ionic mechanisms. Int Rev Neurobiol 21:217-258.

Olave MJ, Puri N, Kerr R, Maxwell DJ (2002) Myelinated and unmyelinated primary afferent axons form contacts with cholinergic interneurons in the spinal dorsal horn. Exp Brain Res 145:448-456.

Ono H, Fukuda H, Kudo Y (1979) Mechanisms of depressant action of baclofen on the spinal reflex in the rat. Neuropharmacology 18:647-653.

Paleckova V, Palecek J, McAdoo DJ, Willis WD (1992) The non-NMDA antagonist CNQX prevents release of amino acids into the rat spinal cord dorsal horn evoked by sciatic nerve stimulation. Neurosci Lett 148:19-22.

Rothlin CV, Katz E, Verbitsky M, Elgoyhen AB (1999) The alpha9 nicotinic acetylcholine receptor shares pharmacological properties with type A gamma-aminobutyric acid, glycine, and type 3 serotonin receptors. Mol Pharmacol 55:248-254.

Rudomin P, Schmidt RF (1999) Presynaptic inhibition in the vertebrate spinal cord revisited. Exp Brain Res 129:1-37.

Rudomin P, Solodkin M, Jiménez I (1987) Synaptic potentials of primary afferent fibers and motoneurons evoked by single intermediate nucleus interneurons in the cat spinal cord. J Neurophysiol 57:1288-1313.

Russo RE, Delgado-Lezama R, Hounsgaard J (2000) Dorsal root potential produced by a TTX-insensitive micro-circuitry in the turtle spinal cord. J Physiol 528:115-122.

Shay BL, Sawchuk M, Machacek DW, Hochman S (2005) Serotonin 5-HT2 receptors induce a long-lasting facilitation of spinal reflexes independent of ionotropic receptor activity. J Neurophysiol 94:2867-2877.

Tata AM, De Stefano ME, Srubek Tomassy G, Vilaró MT, Levey AI, Biagioni S (2004) Subpopulations of rat dorsal root ganglion neurons express active vesicular acetylcholine transporter. J Neurosci Res 75:194-202.

Todd AJ (1996) GABA and glycine in synaptic glomeruli of the rat spinal dorsal horn. Eur J Neurosci 8:2492-2498.

Vyklický L, Syková E, Mellerová B (1976) Depolarization of primary afferents in the frog spinal cord under high $\mathrm{Mg} 2+$ concentrations. Brain Res 117:153-156.

Wall PD (1958) Excitability changes in afferent fibre terminations and their relation to slow potentials. J Physiol 142:1-21.

Willis WD Jr, Coggeshall RE (1991) Sensory mechanisms of the spinal cord. New York: Plenum.

Yasuhara O, Aimi Y, Matsuo A, Kimura H (2008) Distribution of a splice variant of choline acetyltransferase in the trigeminal ganglion and brainstem of the rat: comparison with calcitonin gene-related peptide and substance P. J Comp Neurol 509:436-448. 